\title{
Dinâmica da Água em uma Microbacia com Cobertura Florestal de Eucalipto Localizada na Serra do Mar no Vale do Paraíba do Sul
}

\author{
Rodrigo Trevisan, Luiz Felippe Salemi, Juliano Daniel Groppo, \\ Robson Willians da Costa Silva, Luiz Antonio Martinelli \\ Centro de Energia Nuclear na Agricultura (CENA), Universidade de São Paulo (USP). \\ rttrevisa@yahoo.com.br, piposalemi@gmail.com, julianogroppo@yahoo.com.br \\ rwcsilva@cena.usp.br,zebu@cena.usp.br \\ Jorge Marcos de Moraes \\ Escola de Engenharia de Piracicaba (EEP) \\ jmmoraes@cena.usp.br
}

Recebido: 18/09/11 - revisado: 16/05/12 - aceito: 01/08/12

\begin{abstract}
RESUMO
A conversão da Mata Atlântica original em áreas de agricultura, florestas plantadas, pecuária e outras atividades, têm causado impactos ambientais cujas consequências ainda não foram completamente avaliadas do ponto de vista científico, incluindo estudos hidrológicos em locais onde houve a implantação de florestas de eucalipto. Dentro desse contexto, o objetivo principal do presente trabalho foi o de realizar um estudo hidrológico em uma microbacia com cobertura de eucalipto, próximo ao Parque Estadual da Serra do Mar, núcleo Santa Virgínia. O estudo foi realizado no período de janeiro a dezembro de 2008, e os resultados mostraram que a precipitação foi de $1290 \mathrm{~mm}$, dos quais $14 \%$ foram interceptadas pela vegetação, $38 \%$ foram convertidas em deflúvio e a evapotranspiração foi estimada em $794 \mathrm{~mm}$. O escoamento superfícial foi pouco expressivo, devido à baixa intensidade da precipitação.
\end{abstract}

Palavras-chave: Hidrologia. Mudança do uso do solo. Silvicultura. Eucalipto. Microbacias.

\section{INTRODUÇÃOO}

A Mata Atlântica é a segunda maior floresta no Brasil depois da Amazônia e se estende ao longo da costa atlântica, do Rio Grande do Sul ao sul de Rio Grande do Norte. Ela é mais estreita na região norte que na sul, onde cruza a fronteira brasileira com o Paraguai e Argentina (RIBEIRO et al., 2009).

Essa densa floresta tropical inclui áreas costeiras de floresta inundada de baixa altitude, florestas sub-montanas e montanas (VIEIRA et al., 2008). De acordo com Ribeiro et al. (2009), dos 1.395.849 $\mathrm{km}^{2}$ da floresta original, restavam em 2005, apenas cerca de $163.775 \mathrm{~km}^{2}$ (12\% da área original). A área restante é distribuída, na maior parte dos casos, em pequenos fragmentos inseridos em áreas alteradas por atividades humanas (VIEIRA et al., 2008).

Historicamente, o desmatamento está intimamente relacionado com a exploração econômica de diferentes produtos (METZGER et al., 2009), iniciando a partir do século 16 com a exploração da madeira, seguido pela cana de açúcar, café, pastagens e plantações de eucalipto (DEAN, 1996).

As florestas plantadas estão sempre entre as mais polêmicas atividades agropecuárias, devido principalmente às controvérsias sobre o impacto do eucalipto sobre a dinâmica da água, nutrientes e conservação da biodiversidade (LIMA, 1996).

A hidrologia de microbacias com florestas plantadas tem sido objeto de muitos estudos (JACKSON et al., 2005; SCOTT, 2005; WHITEHEAD; BEADLE, 2004). Estes estudos apresentam os possíveis impactos ambientais desse tipo de floresta, principalmente aqueles relacionados ao consumo de água e perdas de solo e nutrientes.

Há muita discussão e controvérsia sobre a relação entre florestas e água (ANDRÉASSIAN, 2004). Entretanto, diversos trabalhos mostram que, de maneira geral, as microbacias florestadas exibem menor deflúvio anual do que aquelas com cobertura vegetal de menor porte (BROWN et al., 2005; SAHIN; HALL, 1996).

O conhecimento dos componentes do ciclo hidrológico de microbacias é de suma importância 


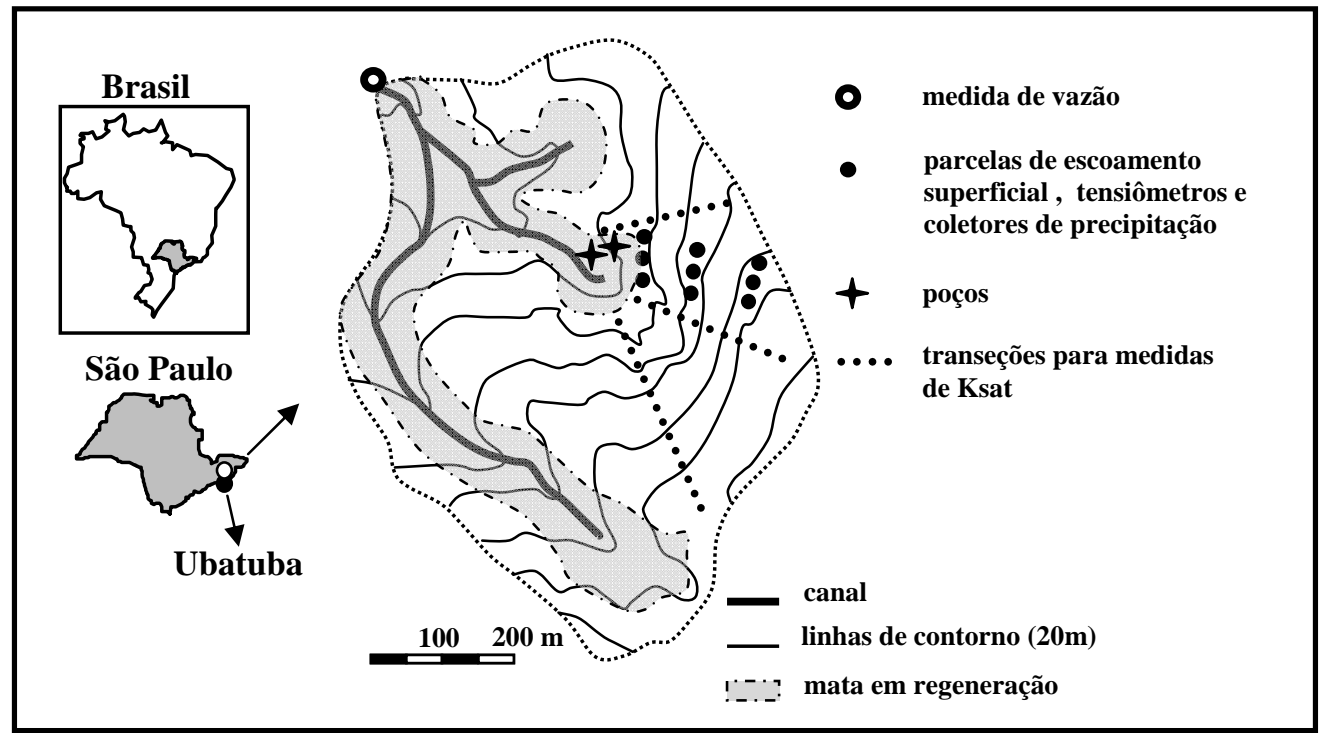

Figura 1 - Localização da microbacia hidrográfica de estudo, mostrando o delineamento experimental, o canal, as linhas de contorno de $20 \mathrm{~m}$ e a área de floresta em regeneração. $\mathrm{Na}$ área restante a cobertura vegetal é de eucalipto

para o manejo sustentável dos recursos naturais e informação básica para diversos estudos ambientais.

Dentro desse contexto, o presente trabalho teve como objetivo estudar uma microbacia hidrográfica com cobertura florestal de eucalipto em região de Mata Atlântica no intuito de analisar as características físicas do solo, os processos hidrológicos e o balanço hídrico.

\section{MATERIAIS E MÉTODOS}

\section{Área de estudo}

O experimento foi realizado em uma microbacia hidrográfica situada no município de São Luis do Paraitinga, na fazenda Sertãozinho II. A mesma está localizada próxima ao Parque Estadual da Serra do Mar, a oeste de Ubatuba-SP (Figura 1). As coordenadas do exutório da microbacia são $23^{\circ} 15^{\prime} 46^{\prime}$ ' S de latitude e $45^{\circ} 09^{\prime} 55^{\prime}$ ' W de longitude, com altitude e declividade média em torno de 1000 $\mathrm{m}$ e $40 \%$, respectivamente. A referida microbacia possui área de aproximadamente de 35,5 ha (23 ha de Eucalyptus urograndis e 12,5 ha de floresta em regeneração em áreas de preservação permanente).

Em relação ao histórico de uso da terra, desde a década de 60, a microbacia estudada era utilizada como pastagem que não sofria qualquer manejo (proprietários e moradores, comunicação pessoal), sendo que antes desse período, não há relatos precisos sobre a atividade exercida e o tipo de vegetação existente na microbacia. Em 2004, realizou-se o plantio de eucalipto (Eucalyptus urograndis com espaçamento $3 \times 2 \mathrm{~m}$ em talhões, onde foram respeitadas as áreas de preservação permanente ao longo dos cursos d'àgua, conforme pode-se verificar na figura 1.

O clima, segundo a classificação de Köeppen, é do tipo Cfa, caracterizado como subtropical, com verões quentes e chuvas bem distribuídas ao longo do ano, com temperatura média de $20{ }^{\circ} \mathrm{C}$. A precipitação média anual no período de 1973 à 2004, medidos pela estação meteorológica da ANA - Agência Nacional de Águas (código - 2345067) localizada à $8 \mathrm{~km}$ da bacia de estudo, é de aproximadamente $1800 \mathrm{~mm}$. No que se refere aos solos, a microbacia apresenta o predomínio de uma associação entre Cambissolo Húmico Distrófico e Cambissolo Háplico Distrófico. Contudo, nas partes mais íngremes onde há o afloramento de rochas, encontram-se Neossolos Litólicos.

\section{Delineamento Experimental}

O delineamento experimental é mostrado na figura 1 , onde pode-se observar o local das medidas de vazão (exutório da microbacia), a vertente onde foram instalados os coletores de precipitação interna e escoamento pelo tronco, as parcelas de escoamento superficial e os tensiômetros, as tran- 
secções para as medidas de condutividade hidráulica do solo em condição de saturação $\left(\mathrm{K}_{\mathrm{sat}}\right)$ e os poços de monitoramento do lençol freático.

Os métodos de amostragem do solo e de monitoramento hidrológico serão descritos sucintamente abaixo. Informações mais detalhadas são apresentadas em Trevisan (2009).

Para a determinação dos atributos físicos do solo, foram coletadas amostras deformadas e não deformadas de solo em quatro profundidades $(0,15$, $0,30,0,50$ e $0,90 \mathrm{~m})$, para a determinação da granulometria e da densidade do solo, respectivamente, nos mesmos locais onde foram instalados os equipamentos de monitoramento hidrológico. As medidas da $\mathrm{K}_{\mathrm{sat}}$ foram realizadas em transeções no sentido canal-divisor de águas, utilizando um permeâmetro compacto de carga constante ("Amoozemeter"), com método similar ao empregado por Elsenbeer, Cassel e Castro (1992).

A precipitação foi medida através de um pluviógrafo tipo basculante (RainLog, RainWise, Inc) instalado em uma área aberta ao lado da microbacia. Este registrou a quantidade de água precipitada em intervalos de tempo de 5 minutos. A precipitação que passa pelo dossel da floresta (precipitação interna) foi medida semanalmente utilizando dez coletores de PVC com $2 \mathrm{~m}$ de comprimento com uma abertura transversal de $0,15 \mathrm{~m}^{2}$ de área, ligados a um galão, similar ao descrito por Laclau et al. (2003). A quantificação semanal do escoamento pelo tronco seguiu metodologia proposta por Balieiro, Cunha e Franco (2001).

A quantificação semanal do escoamento superficial foi determinada através da instalação de nove parcelas de dimensões com $1,5 \mathrm{~m} \times 1,5 \mathrm{~m}$, distribuídas em triplicata, em três pontos da vertente: superior, médio e inferior. $\mathrm{O}$ ponto superior foi instalado próximo ao divisor topográfico, o inferior próximo ao canal fluvial, porém fora da área de preservação permanente, e o ponto médio entre esses dois últimos.

O potencial matricial da água do solo foi medido através de três baterias de tensiômetros comuns de cápsula porosa, nas profundidades de $0,15,0,30,0,50$ e $0,90 \mathrm{~m}$, nos mesmos três pontos da vertente utilizados para as parcelas de escoamento superficial descritos anteriormente. Semanalmente, as medidas de tensão em cada tensiômetro foram realizadas com o auxilio de um manômetro digital (Bringer "digital pressure gauge").

O monitoramento do lençol freático foi realizado por meio de dois poços de observação localizados próximo ao canal da microbacia. Entre- tanto, os resultados não serão apresentados no presente trabalho.

A medição da vazão da microbacia foi efetuada no leito natural do rio,uma vez que não foi autorizada a construção de vertedores ou calhas no local. Foi então instalada uma régua e um sensor eletrônico de nível de água acoplado a um registrador ("Water Level Sensor", Trutrack) e a velocidade nos diversos pontos do canal, necessária para a estimativa da vazão, foi medida através de um molinete (FP201 "Flow Probe", GlobalWater) ou com flutuadores quando o nível da água estava muito baixo. Através dos dados de cota e vazão, elaborou-se então a curva-chave e sua equação (COMPANHIA DE TECNOLOGIA DE SANEAMENTO AMBIENTAL, 1978; PORTO; et al 2003). A cota foi medida a cada cinco minutos, e portanto, a vazão também determinada nesse passo de tempo.

\section{Análises Estatísticas}

Usando o teste de normalidade ShapiroWilk $(p<0,01)$ presente no pacote estatístico STATISTICA 6.0 (StatSoft), observou-se que os dados de $\mathrm{K}_{\text {sat }}$ não apresentaram distribuição normal (ALTMAN e BLAND, 1994). Desta forma, utilizou-se a mediana como a medida de maior representatividade da posição central do conjunto de dados (ELSENBEER; et al, 1992).

\section{Separação de hidrogramas e balanço hídrico}

A estimativa do escoamento de base e do escoamento direto foi realizada por meio da separação de hidrogramas, utilizando o metodo proposto por Chow, Maidment e Mays (1988), no qual durante um evento, o comportamento do escoamento de base é representado por uma linha reta entre o início das ascensão da vazão e o ponto de inflexão da recessão.

O balanço hídrico foi determinado por meio da equação simplificada apresentada por Fill (1987), que considera a variação do armazenamento de água no solo como sendo desprezível entre duas estações úmidas consecutivas.

$\mathrm{P}-\mathrm{ET}=\mathrm{D}$

Onde: P é a Precipitação; ET é a evapotranspiração e $\mathrm{D}$ o deflúvio. 


\section{RESULTADOS}

\section{Atributos físicos do solo}

Os resultados de granulometria do solo nas três posições da vertente (baixo, médio e alto) para as profundidades $0,15,0,30,0,50$ e $0,90 \mathrm{~m}$ mostram que houve um aumento no conteúdo de argila em profundidade (Figura 2). Próximo à superfície o teor de argila no solo variou entre 30 a $35 \%$ nas três posições ao longo da vertente, caracterizando textura média, passando a textura argilosa nas camadas mais profundas do perfil.

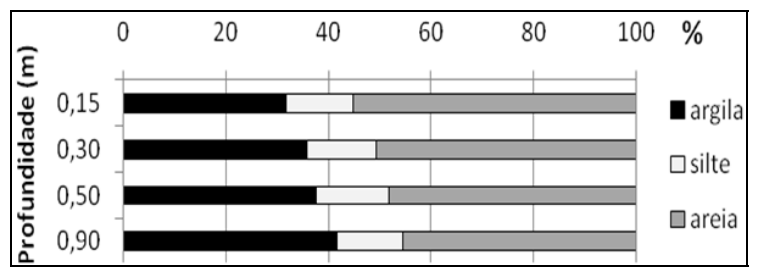

Figura 2 - Valores médios da porcentagem de argila, silte e areia nos três pontos de amostragem de solos

A $\mathrm{K}_{\mathrm{sat}}$ decresceu com a profundidade passando de aproximadamente $40 \mathrm{~mm} \mathrm{~h}^{-1}$ a $0,15 \mathrm{~m}$ para somente $2 \mathrm{~mm} \mathrm{~h}^{-1}$ a $0,90 \mathrm{~m}$ (Figura 3).

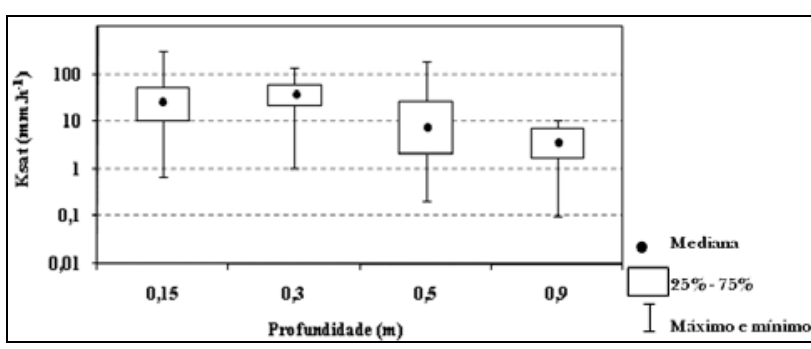

Figura 3 - Diagrama de caixas ("Box-Plot") exibindo mediana, inter quartil (25\% - 75\%) e barras de valores máximos e mínimos de $K_{\mathrm{sat}}$ nas profundidades das medidas realizadas na microbacia com eucalipto

A densidade do solo variou entre 1,32 e 1,38 $\mathrm{mg} \mathrm{m}^{-3}$, não havendo clara relação entre profundidade e densidade (Figura 4). Para efeito de comparação, os resultados são apresentados juntamente com valores obtidos em Floresta Ombrófila Densa (GROPPO, 2010) e em uma pastagem (SALEMI, 2009), localizadas a $10 \mathrm{~km}$ e 19,5 km, respectivamente, da área do presente estudo. Pode-se observar na figura 4 que as diferenças mais notáveis com relação aos resultados da densidade obtidos no eucalipto, ocorrem nas profundidades 0,15 e $0,30 \mathrm{~m}$, onde os valores da floresta são expressivamente menores e nas profundidades 0,30 e $0,50 \mathrm{~m}$ onde os valores do pasto são maiores.

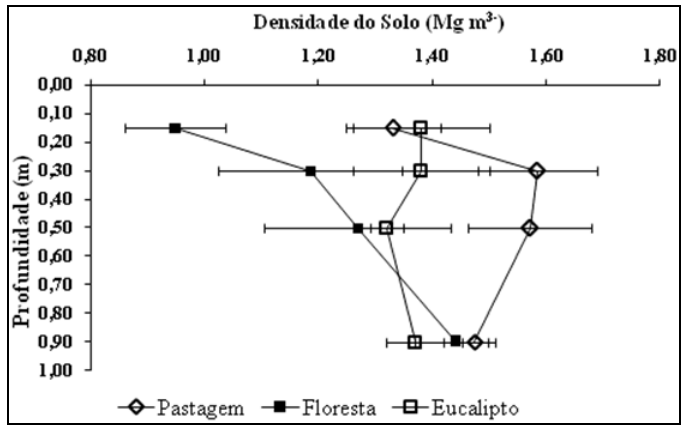

Figura 4 - Densidade do solo a 0,15, 0,30, 0,50 e 0,90 $\mathrm{m}$ de profundidade na floresta nativa (GROPPO, 2010), pastagem (SALEMI, 2009) e eucalipto (presente estudo)

\section{Precipitação, Interceptação Vegetal e Escoamento superficial nas parcelas}

A precipitação medida no período de estudo (janeiro a dezembro de 2008), foi de $1290 \mathrm{~mm}$. Os percentuais dos eventos em intervalos de tempo de cinco minutos e da contribuição para o total anual de precipitação, em classes de intensidade, mostram que aproximadamente $70 \%$ dos eventos ocorrem na faixa de 0 a $5 \mathrm{~mm} \mathrm{~h}^{-1}$ e correspondem a $35 \%$ do total da chuva nesse período (Figura 5).

A interceptação correspondeu aproximadamente a $14 \%$, conseqüentemente, $86 \%$ atingiu à superfície do solo, sendo $81 \%$ pela precipitação interna e $5 \%$ pelo escoamento pelo tronco.

Os coeficientes de escoamento superficial nas parcelas nas três porções da vertente foram muito baixos. O valor médio foi de apenas $2 \%$ do total precipitado.

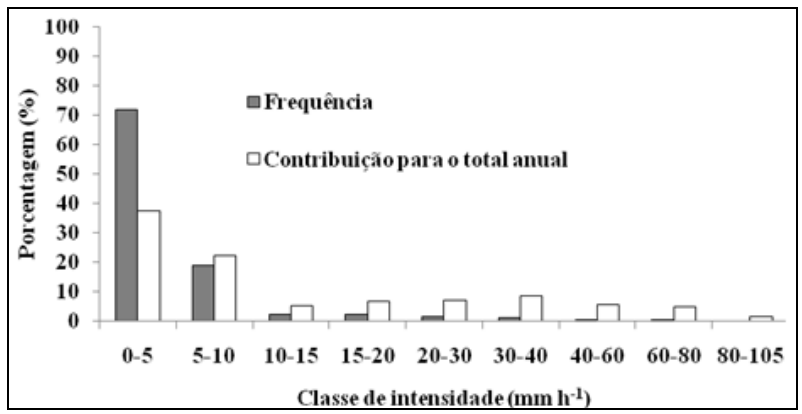

Figura 5 - Distribuição de precipitação em classes de intensidade e sua contribuição para o total anual 

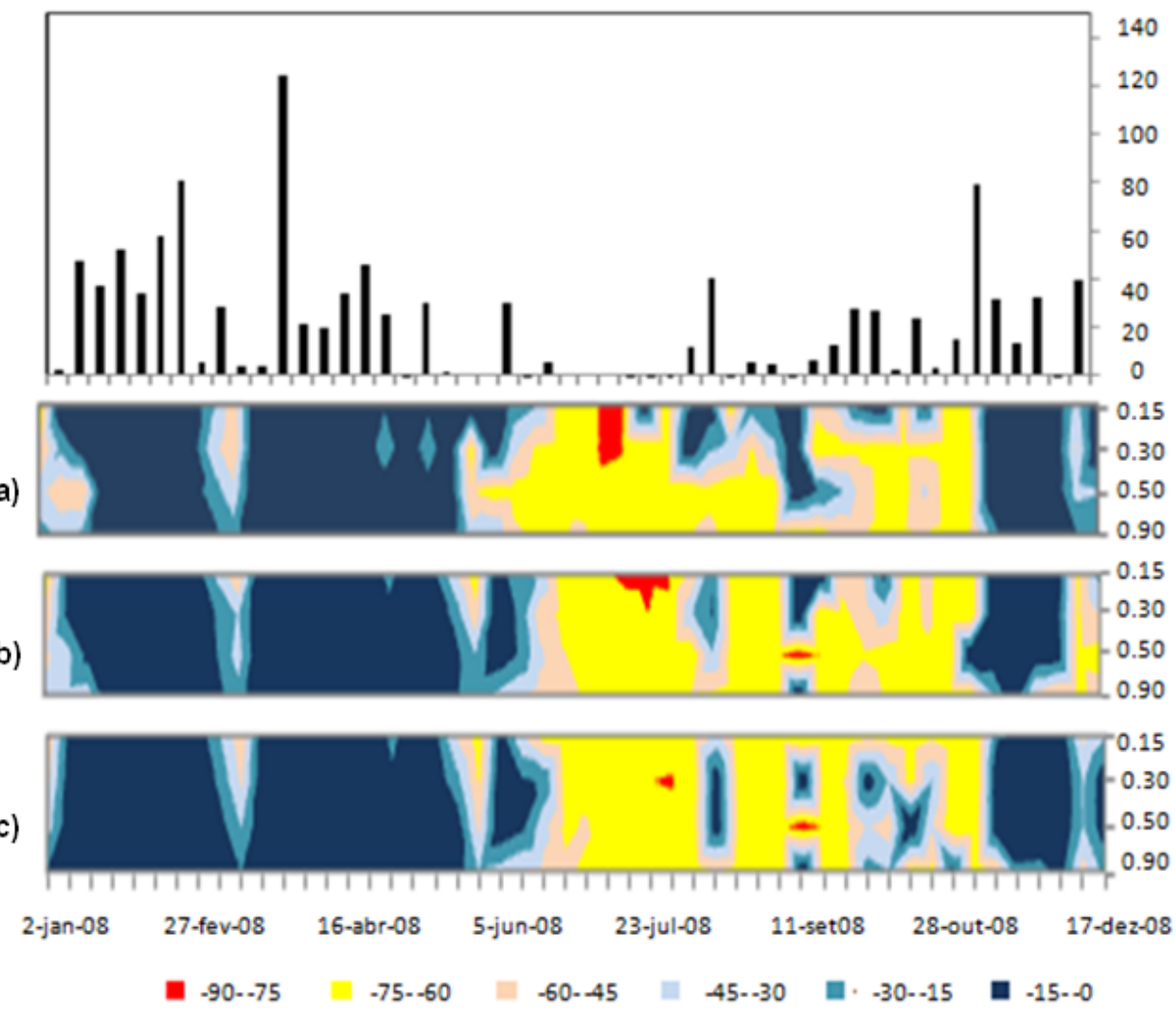

Figura 6 - (a) Precipitação semanal em milímetros e tensão da água no solo (kPa) nas posições (b) superior, (c) mediana e (d) inferior da vertente

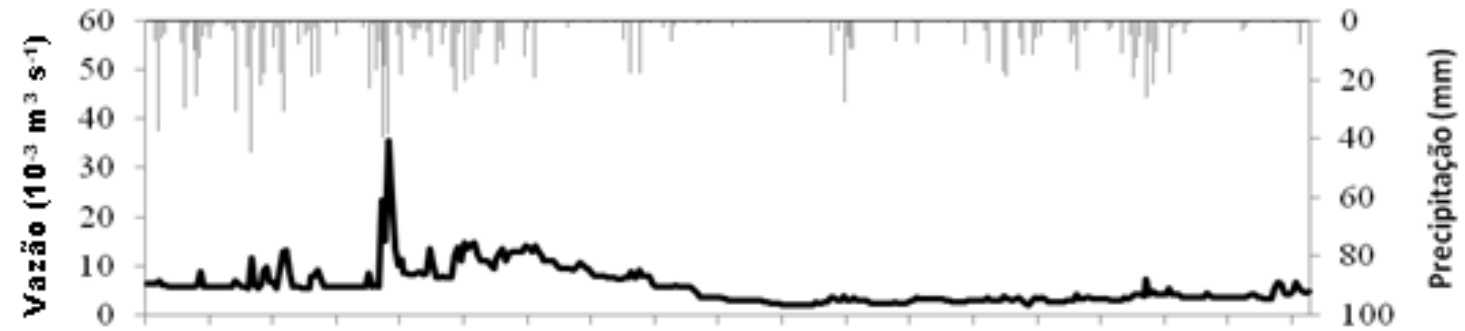

Figura 7 - Precipitação diária (mm) e média diária da vazão $\left(\mathrm{m}^{3} \mathrm{~s}^{-1}\right)$ durante o período de 01/01/2008 a 30/12/2008

\section{Umidade do solo}

A umidade do solo, como mostrado na figura 6 através do potencial matricial, permanece entre novembro e maio com valores entre 0 e $-15 \mathrm{kPa}$, ou seja, bastante úmido. Comportamento similar foi encontrado em locais próximos ao do presente estudo na época úmida por Groppo (2010) e Salemi
(2009), em trabalhos desenvolvidos em Floresta Ombrofila Densa e em pastagem, respectivamente. No período mais seco, entre junho e outubro, as tensões permaneceram na maior parte do tempo na faixa entre -75 e $-90 \mathrm{kPa}$. Os potenciais matriciais do presente estudo foram mais baixos (negativos) que os encontrados por Groppo (2010) e Salemi (2009). 
Vazão

O hidrograma e o hietograma do período de estudo são apresentados na figura 7. A vazão média medida no exutório no período estudado foi de aproximadamente $5,7 \quad 10^{-3} \mathrm{~m}^{3} \mathrm{~s}^{-1}$, havendo um máximo de $35,010^{-3} \mathrm{~m}^{3} \mathrm{~s}^{-1}$ no dia 17 de março e um mínimo de 1,8 $10^{-3} \mathrm{~m}^{3} \mathrm{~s}^{-1}$ no dia 16 de junho de 2008 .

\section{Separação de Hidrogramas e Balanço Hídrico}

Por meio da separação de hidrogramas, observou-se que o escoamento de base contribuiu com aproximadamente $87 \%$ para o deflúvio e o escoamento direto com apenas $13 \%$.

Os resultados do monitoramento realizado na microbacia no período de estudo, mostraram uma precipitação de 1290 mm e um deflúvio de 496 $\mathrm{mm}$. O balanço hídrico simplificado indicou que o valor da evapotranspiração real foi de $794 \mathrm{~mm}$.

\section{DISCUSSÃO}

A condutividade hidráulica do solo em condição de saturação $\left(\mathrm{K}_{\mathrm{sat}}\right)$ apresentou uma grande variabilidade devido à heterogeneidade espacial do solo. Essa variabilidade já foi observada por outros autores em estudos similares (ELSENBEER et al., 1992 e 1999; MORAES et al., 2003). Os altos valores encontrados de $\mathrm{K}_{\mathrm{sat}}$ próximo à superfície do solo $(0,15 \mathrm{~m}$ e $0,30 \mathrm{~m})$ podem ser atribuídos a alteração da distribuição dos poros devido à penetração das raízes e a presença de uma camada de serapilheira. Além disso, a constante adição de matéria orgânica na superfície por meio da queda de folhas e ramos cria condições favoráveis ao desenvolvimento da macro e micro fauna que, por sua vez, aumenta a porosidade do solo. A influência dos fatores acima diminui com o aumento da profundidade, o que justifica, em parte, o decréscimo dos valores de $\mathrm{K}_{\mathrm{sat}}$ nas camadas mais profundas do solo. Adicionalmente, corroborando com esse decréscimo, existe um aumento no teor de argila com a profundidade, como observado na figura 2.

Em termos de densidade do solo, diferenças significativas foram encontradas entre os diferentes usos do solo (Figura 4). No que se refere à floresta, os valores de densidade desta são menores próximo a superfície, principalmente nas profundidades 0,15 $\mathrm{m}$ e $0,30 \mathrm{~m}$, devido provavelmente à maior densidade de raízes e atividade biótica. Já em relação à pastagem, ambas as áreas apresentam valores similares de $\mathrm{K}_{\mathrm{sat}}$ na superfície, provavelmente, decorrentes do adensamento do solo devido ao impacto das gotas de chuva e pisoteio do gado que provoca a compactação na pastagem, e as atividades de plantio e manejo no caso do eucalipto. Deve-se considerar também que o uso do solo antes do plantio do eucalipto também era pastagem. Assim, muito provavelmente houve compactação do solo mesmo antes do uso da terra ser eucalipto. Na profundidade de $0,50 \mathrm{~m}$, a densidade do eucalipto é menor que a da pastagem, provavelmente, devido à maior densidade de raízes. Com relação à floresta, os valores são nitidamente diferentes nas camadas mais superficiais, onde a floresta apresenta valores expressivamente menores, devido, provavelmente, ao fato da já explanada existência de maior camada de serapilheira, raízes de plantas de sub-bosque e atividades bióticas.

A heterogeneidade do perfil do solo tem consequências importantes nos processos hidrológicos, podendo gerar escoamento superficial em regiões saturadas e ainda o surgimento de um lençol freático suspenso e escoamento subsuperficial, decorrentes principalmente da camada de impedimento na profundidade de $0,50 \mathrm{~m}$, onde ocorre um decréscimo acentuado de $\mathrm{K}_{\mathrm{sat}}\left(6 \mathrm{~mm} \mathrm{~h}^{-1}\right)$. As chuvas de baixa intensidade, que predominaram na microbacia no período de estudo (Figura 4), na maior parte dos eventos, não excederam os valores de $\mathrm{K}_{\text {sat }}$ próximo à superfície do solo, o que favorece a infiltração e percolação da água no solo. Essa constatação justifica os valores reduzidos do coeficiente anual de escoamento superficial nas parcelas (Escoamento Superficial/Precipitação $=0,02)$, do coeficiente de deflúvio da microbacia (Vazão/Precipitação $=0,38)$ e também o atraso na resposta da maior vazão mensal com relação aos meses de maior precipitação de aproximadamente dois meses (TREVISAN, 2009).

O potencial matricial da água do solo, mostrado na figura 6 , permanece entre novembro e maio com valores entre 0 e $-15 \mathrm{kPa}$, ou seja, o solo permanece bastante úmido o que torna possível a recarga do lençol freático. Comportamento similar foi encontrado na época úmida por Groppo (2010) e Salemi (2009), em trabalhos desenvolvidos, em floresta Ombrofila Densa e em pastagem, respectivamente. Esse comportamento mostra que o uso do solo não apresenta grande influencia sobre a umidade do solo em períodos de excedente hídrico. Já no período mais seco, entre junho e outubro, as tensões permaneceram na maior parte do tempo na faixa entre -75 e $-90 \mathrm{kPa}$, e os potenciais matriciais do presente estudo foram mais baixos (negativos), que os encontrados por Groppo (2010) e Salemi 
(2009). É necessário colocar aqui, que a precipitação efetiva (precipitação total menos a interceptação) no período de seca foi 186, 226 e $228 \mathrm{~mm}$ na bacia de eucalipto, floresta e pasto, respectivamente. Apesar de ligeiramente diferentes, esses resultados mostram que a retirada de água pelas raízes do eucalipto foi maior que a dos dois outros tipos de uso da terra. Resultados similares foram observados por Calder et al. (1997), comparando a umidade do solo sob eucalipto (Eucalyptus camaldulensis), teca (Tectona grandis), Artocarpus heteropylllus e Eleusine coracana. No referido estudo, o eucalipto foi a espécie que mais rapidamente reduziu a quantidade de água no solo.

Lima (1996) relata que no período de pouca chuva, o solo sob eucalipto tende a apresentar potenciais matriciais mais negativos de modo mais rápido que uma vegetação natural. $\mathrm{O}$ autor relata ainda que a extração de água ocorre principalmente na camada superficial já que possui um sistema radicular abundante, bem distribuído lateralmente e que se concentra na camada superficial do solo, fato também evidenciado por Talsma e Gardner (1986). Essa alta taxa de extração de água do solo pode ser explicada pela alta taxa de produtividade primária, implicando na utilização da água disponível do solo (SCOTT, 2005). Da mesma forma, Almeida e Soares (2003) relataram que no período de pouca chuva, geralmente a quantidade de água no solo, em florestas de eucalipto, tendem a ser menores que em florestas de Mata Atlântica, devido às raízes das árvores de mata natural atingirem profundidades de até 5 $\mathrm{m}$, enquanto as raízes de eucalipto não ultrapassam 2,5 m. Segundo esses autores, a Mata Atlântica utiliza água de camadas mais profundas do solo do que o eucalipto, o que acarreta numa menor extração de água da porção superficial do solo.

Os valores do coeficiente de escoamento superficial encontrados no período de estudo $(0,02)$ são da mesma ordem de grandeza daqueles encontrados por Lima et al. (1996), que foi de 0,024, para uma microbacia de 68,2 ha reflorestada com Eucalyptus saligna, na cidade de Itatinga - SP. Lima (1988) comparou o escoamento superficial de uma área de cobertura florestal de Eucalyptus grandis com uma área de solo desnudo durante quatro anos, do inicio do plantio do eucalipto até o quarto ano. Este autor encontrou na área plantada com eucalipto uma maior proporção de escoamento superficial no primeiro ano $(0,03)$ e menores no ultimo ano $(0,01)$. Por outro lado, na área que apresentava solo exposto, o mesmo autor encontrou valores de escoamento superficial semelhante àqueles encontrados no eucalipto no primeiro ano de plantio. Martins et al. (2003) encontraram valores de coeficiente de escoamento superficial de 0,02, 0,01 e 0,05 em áreas de eucalipto, floresta nativa e solo sem cobertura, respectivamente.

A análise de alguns hietogramas do período chuvoso mostrou a existência de precipitações com intensidades que ultrapassam os valores de $\mathrm{K}_{\mathrm{sat}}$ próximo a superfície $\left(40 \mathrm{~mm} \mathrm{~h}^{-1}\right)$. Considerando que a umidade do solo no período é alta, a capacidade de infiltração tende a se aproximar do valor de $\mathrm{K}_{\mathrm{sat}}$, mostrando a possível ocorrência de escoamento superficial hortoniano na microbacia. No período seco, alguns eventos também apresentaram intensidades maiores que o valor de $\mathrm{K}_{\mathrm{sat}}$ próximo a superfície, entretanto, como o solo apresentou maior potencial matricial, a capacidade de infiltração foi maior o que torna pouco provável a geração de escoamento superficial hortoniano.

Em locais próximos ao do presente estudo, coeficientes de deflúvio de 0,38 e 0,51 foram encontrados por Groppo (2010) e Salemi (2009) em área de floresta e pastagem, respectivamente. A geração de vazão semelhante entre a floresta e de eucalipto pode ser interpretado como uma espécie de mecanismo de compensação entre a interceptação e o armazenamento de água. A interceptação é maior na floresta $(35 \%$ contra $14 \%$ no eucalipto), reduzindo a chuva que efetivamente atinge o solo. Por outro lado, o armazenamento da água no solo é menor no eucalipto devido à maior extração de água pelas raízes. A maior geração de vazão da pastagem em relação aos outros dois usos do solo está de acordo com diversos outros estudos encontrados na literatura (e.g. MORAES et al., 2006).

Em termos de evapotranspiração anual calculado pelo balanço de massa, nota-se que o valor de 794 mm está dentro do intervalo de 569 a 1514 encontrados no Brasil (ALMEIDA; OLIVEIRA; KLIEMANN, 2007; ALMEIDA; SOARES, 2003; CABRAL et al., 2010; LIMA et al., 1996; RANZINI; LIMA, 2002).

\section{CONCLUSÕES}

A precipitação em 2008 foi de $1290 \mathrm{~mm}$ e o deflúvio de $496 \mathrm{~mm}$. Por meio do balanço hídrico simplificado, a evapotranspiração obtida foi de 794 $\mathrm{mm}$.

A capacidade de infiltração do solo foi quase sempre superior a intensidade de chuva predominante na microbacia $(70 \%$ com valores inferiores 
a $\left.5 \mathrm{~mm} \cdot \mathrm{h}^{-1}\right)$, o que favorece a infiltração da água no solo e desse modo há a pouca geração do escoamento superficial hortoniano e a predominância do escoamento de base ( $87 \%$ da contribuição total) na geração do deflúvio.

Sob o regime de precipitação, o coeficiente de deflúvio $(0,38)$ foi similar ao encontrado em mata nativa em bacia vizinha ao presente estudo no mesmo período. Esses valores mostram que apesar da maior retirada de água pelas raízes na bacia de eucalipto a interceptação na bacia florestada foi bem maior ( $35 \%$ na floresta e $14 \%$ no eucalipto). Há que se salientar que os resultados mostram o comportamento da bacia para apenas um ano de monitoramento.

\section{REFERÊNCIAS}

ALMEIDA, A. C.; SOARES, J. V. Comparação entre uso de água em plantações de Eucalyptus grandis e floresta ombrófila densa (Mata Atlântica) na costa Leste do Brasil. Revista Árvore, v. 27, n. 2, p. 159-170, 2003.

ALMEIDA, R. A.; OLIVEIRA, L. F. C.; KLIEMANN, H. J. Eficiência de Espécies Vegetais na Purificação do Esgoto Sanitário. Pesquisa Agropecuária Tropical, v. 37, n. 1, p. 1-9, 2007.

ALTMAN, D. G.; BLAND, J. M. Quartiles, quintiles, centiles and other quantiles. British Medical Journal, v. 309, n. 6960, p. 996, 1994.

ANDRÉASSIAN, V. Waters and Forests: From Historical Controversy to Scientific debate. Journal of $\mathrm{Hy}$ drology, v. 291, n. 1-2, p. 1-27, 2004.

BALIEIRO, F. C.; CUNHA, C. F.; FRANCO, A. A. Coletor de água para avaliação do escorrimento em tronco de espécies arbóreas. Revista Árvore, v. 25, n. 2, p. 167-173, 2001.

BROWN, A. E.; ZHANG, L.; McMAHON, T. A.; WESTERN, A. W.; VERTESSY, R. A. A review of paired catchment studies for determining changes in water yield resulting from alteration in vegetation. Journal of Hydrology, v. 310, n. 1-4, p. 28-61, 2005.

CABRAL, O. M. R.; ROCHA, H. R.; GASH, J. H. C.; MARSDEN, C.; LIGO, M. A. V.; FREITAS, H. C.; TATSCH, J. D.; BRASÍLIO, E. M. S.; GOMES, E. The energy and water balance of a Eucalyptus plantation in southeast Brazil. Journal of Hydrology, v. 388, n. 3-4, p. 208-216, 2010.

CALDER, I. R.; ROSIER, P. T. W.; PRASANNA, K. T.; PARAMESWARAPPA, S. Eucalyptus water use greater than rainfall input - a possible explanation from southern India. Hydrology $\mathcal{E}$ Earth System Sciences, v. 1, n. 2, p. 249-257, 1997.

CHOW, V. T.; MAIDMENT, D. R.; MAYS, L. W. Applied hydrology. New York: McGraw-Hill, 1988.

COMPANHIA DE TECNOLOGIA DE SANEAMENTO AMBIENTAL. Normalização Técnica L 4001. São Paulo, 1978.

DEAN, W. A ferro e fogo: a história e a devastação da Mata Atlântica brasileira. São Paulo: Companhia das Letras, 1996.

ELSENBEER, H.; CASSEL, K.; CASTRO, J. Spatial analysis of soil hydraulic conductivity in a tropical rain forest catchment. Water Research Resources, v. 28, n. 12, p. 3201-3214, 1992.

ELSENBEER, H.; NEWTON, B. E.; DUNNE, T.; MORAES, J. M. Soil hydraulic conductivities of latosols under forest, pasture and teak in Rondônia, Brazil. Hydrological Processes, v. 13, n. 9, p. 1417-1422, 1999.

FILL, H. D. Informações hidrológicas. In: BARTH, F. T.; POMPEU, C. T.; FILL, H. D.; TUCCI, C. E. M.; KELMAN, J.; BRAGA JUNIOR, B. P. F. Modelos para gerenciamento de recursos hídricos. São Paulo: $\mathrm{ABRH}$, 1987. cap. 2, p. 95-210.

GROPPO, J.D. Caracterização hidrológica e dinâmica do nitrogênio em uma microbacia com cobertura florestal (Mata Atlântica), no Parque Estadual da Serra do Mar, Núcleo Santa Virgínia. 81 f. 2010. Tese (Doutorado em Ciências) - Centro de Energia Nuclear na Agricultura, Universidade de São Paulo, Piracicaba, 2010.

JACKSON, R. B.; JOBBÁGY, E. G.; AVISSAR, R.; ROY, S. B.; BARRET, D. J.; COOK, C. W.; FARLEY, K. A.; MAITRE, D. C.; McCARL, B. A.; MURRAY, B. C. Trading Water for Carbon with Biological Carbon Sequestration. Science, v. 310, n. 5756, p. 1944-1947, 2005.

LACLAU, J. P.; RANGER, J.; BOUILLETA, J. P.; DIEU NZILAC, J.; DELEPORTE, P. Nutrient cycling 
in a clonal stand of Eucalyptus and adjacent savanna ecosystem in Congo. Chemical composition rainfall, throughfall and stemflow solutions. Forest Ecology and Management, v. 176, n. 1-3, p. 105-119, 2003.

LIMA, W. P. Escoamento superficial, perdas de solo e de nutriente em microparcelas reflorestadas com eucalipto em solos arenosos no município de São Simão, SP. IPEF, Piracicaba, n. 38, p. 5-16, 1988.

LIMA, W. P. Impacto ambiental do eucalipto. 2. ed. São Paulo: EDUSP, 1996.

LIMA, W. P.; MOREIRA, R. M.; SCARDUA, F. P.; MASETTO, A. V. Hidrologia de uma microbacia com cobertura de floresta de eucalipto com 50 anos de idade na estação experimental de Itatinga, Estado de São Paulo. Scientia Forestalis, n. 50, p. 11-19, 1996.

MARTINS, S. G.; SILVA, M. L. N.; CURI, N.; FERREIRA, M. M.; FONSECA, S.; MARQUES, J. J. G. S. M. Perdas de solo e água por erosão hídrica em sistemas florestais na região de Aracruz, Estado de Espírito Santo - Brasil. Revista Brasileira de Ciência do Solo, v. 27, n. 3, p. 395-403, 2003.

METZGER, J. P.; MARTENSEN, A. C.; DIXO, M.; BERNACCI, L. C.; RIBEIRO, M. C.; TEIXEIRA, A. M. G.; PARDINI, R. Time-lag in biological responses to landscape changes in a highlydynamic Atlantic forest region. Biological Conservation, v. 142, n. 6, p. 1166-1177, 2009.

MORAES, J. M.; SCHULER, A. E.; DUNNE, T.; FIGUEIREDO, R. O.; VICTORIA, R. L. Water storage and runoff processes in plinthic soils under forest and pasture in Eastern Amazonia. Hydrological Processes, v. 20, n. 12, p. 2509-2526, 2006.

MORAES, J. M.; SCHULER, A. E.; GUANDIQUE, M. E. G.; MILDE, L. C.; GROPPO, J. D.; MARTINELLI, L. A.; VICTORIA, R. L. Propriedade física dos solos na parametrização de modelos hidrológicos. Revista Brasileira de Recursos Hídricos, v. 8, n. 1, p. 61-70, 2003.

PORTO, R. L.; FILHO, K. Z.; SILVA, R. M. Medição de vazão e curva chave. São Paulo: Escola Politécnica/USP, 2003.

RANZINI, M.; LIMA, W. P. Comportamento hidrológico, balanço de nutrientes e perdas de solo em duas microbacias reflorestadas com Eucalyptus, no
Vale do Paraíba, SP. Scientia Florestalis, n. 61, p. 144159, 2002.

RIBEIRO, M. C.; METZGER, J. P.; MARTENSEN, A. C.; PONZONI, F. J.; HIROTA, M. M. The Brazilian Atlantic Forest: How much is left, and how is the remaining forestdistributed? Implications for conservation. Biological Conservation, v. 142, n. 6, p. 1141-1153, 2009.

SAHIN, V.; HALL, M. J. The effects of forestation and deforestation on water yields. Journal of Hydrology, v. 178, n. 1-4, p. 293-309, 1996.

SALEMI, L. F. Balanço de água e de nitrogênio em uma microbacia coberta por pastagem no litoral norte do Estado de São Paulo. 2009. 93 f. Dissertação (Mestrado em Ecologia Aplicada) - Escola Superior de Agricultura "Luiz de Queiroz", Universidade de São Paulo, Piracicaba, 2009

SCOTT, D. F. On the Hydrology of industrial timber plantations. Hydrological Processes, v. 19, n. 20, p. 4203-4206, 2005.

TALSMA, T.; GARDNER, E. A. Soil water extraction by a mixed Eucalypt Forest during a drought period. Australian Journal of Soil Research, v. 24, n. 1, p. 25-32, 1986.

TREVISAN, R. Estudo do balanço hídrico e da dinâmica do nitrogênio em uma microbacia com plantação florestal de eucalipto no litoral norte do estado de São Paulo. 2009. 111 f. Dissertação (Mestrado em Química na Agricultura e Meio Ambiente) - Centro de Energia Nuclear na Agricultura, Universidade de São Paulo, Piracicaba, 2009.

VIEIRA, S. A.; ALVES, L. F.; AIDAR, M. P. M.; ARAÚJO, L. S.; BAKER, T.; BATISTA, J. L. F.; CAMPOS, M. C. R.; CAMARGO, P. B.; CHAVE, J.; DELITTI, W. B.; HIGUCHI, N.; HONÓRIO, E.; JOLY, C. A.; KELLER, M.; MARTINELLI, L. A.; DE MATTOS, E. A.; METZKER, T.; PHILlIPS, O.; SANTOS, F. A. M.; SHIMABUKURO, M. T.; SILVEIRA, M.; TRUMBORE, S. E. Estimation of biomass and carbon stocks: the case of the Atlantic Forest. Biota Neotropica, v. 8, n. 2, p. 21-29, 2008.

WHITEHEAD, D.; BEADLE, C. Physiological regulation of productivity and water use in Eucalyptus: a review. Forest Ecology and Management, v. 193, p. 113140, 2004. 
Water Dynamics in a Micro-basin With Eucalyptus Forest Cover Located in the Serra do Mar Mountains in Paraíba do Sul Valley

\section{ABSTRACT}

The conversion of the original Atlantic Forest into areas for agriculture, planted forests, cattle and other activities have caused environmental impacts whose consequences have not yet been completely evaluated scientifically, including hydrological studies in places where eucalyptus forests had been planted. . In this context, the main objective of the present paper was to carry out an hydrological study in a micro-basin covered with eucalyptus forest, near Parque Estadual da Serra do Mar(State Park), Santa Virginia nucleus. The study was performed from January to December of 2008 and the results showed that the precipitation was $1290 \mathrm{~mm}$, where $14 \%$ was intercepted by the vegetation, $38 \%$ were converted in streamflow and the evapotranspiration was estimated as about $794 \mathrm{~mm}$. The surface runoff was of little significance, due to a low intensity of the precipitation.

Key-words: Hydrology, Land use change, Forestry, Eucalyptus, Micro-basins. 